\title{
Can Natural Killer Cells Be a Principal Player in Anti-SARS-CoV-2 Immunity?
}

\author{
Faria Ahmed ${ }^{1}$, Dong-Hyeon $\mathrm{Jo}^{2}$ and Seung-Hwan Lee $\mathrm{L}^{2,3 *}$ \\ 1 Department of Nursing, Faculty of Health Sciences, University of Ottawa, Ottawa, ON, Canada, ${ }^{2}$ Department of \\ Biochemistry, Microbiology, and Immunology, Faculty of Medicine, University of Ottawa, Ottawa, ON, Canada, \\ ${ }^{3}$ The University of Ottawa Centre for Infection, Immunity, and Inflammation, Faculty of Medicine, University of Ottawa, \\ Ottawa, ON, Canada
}

Keywords: natural killer cells, immunotherapy, immunomodulatory, COVID-19, SARS-CoV-2 infection

\section{OPEN ACCESS INTRODUCTION}

Edited by:

Hans A. R. Bluyssen,

Adam Mickiewicz University, Poland

Reviewed by:

Gerard Chaouat, INSERM U976 Immunologie, Dermatologie, Oncologie, France Claudia Cantoni,

University of Genoa, Italy

*Correspondence:

Seung-Hwan Lee Seunglee@uottawa.ca

Specialty section: This article was submitted to Molecular Innate Immunity, a section of the journal Frontiers in Immunology

Received: 24 July 2020 Accepted: 11 November 2020 Published: 07 December 2020

Citation:

Ahmed F, Jo D-H and Lee S-H (2020) Can Natural Killer Cells Be a Principal Player in Anti-SARS-CoV-2 Immunity?

Front. Immunol. 11:586765. doi: 10.3389/fimmu.2020.586765
The spread of the coronavirus disease 2019 (COVID-19) pandemic has led to disastrous consequences, impacting social, economic, and medical systems, spanning both developed and developing countries (1). According to the World Health Organization, there have been over 35 million confirmed cases of COVID-19 at the time of writing, with over a million deaths worldwide (2). Within the larger Coronaviridae family, alpha-, beta-, gamma-, and delta-coronavirus genera are able to infect a variety of hosts (1). The beta coronaviruses $(\beta-\mathrm{CoV})$ are notorious for having caused the Severe Acute Respiratory Syndrome (SARS) epidemic, the Middle East Respiratory Syndrome (MERS) epidemic, and now the COVID-19 pandemic. COVID-19 is caused by the SARS-CoV-2 virus, following the SARS-CoV and MERS-CoV, which caused the SARS and MERS epidemics, respectively (3-6).

Clinical manifestations of SARS-CoV-2 infection among symptomatic individuals can include cough, weakness, fever, and a spectrum of less common symptoms such as sore throat, rhinorrhea, hemoptysis, lymphopenia, and diarrhea (4, 7-10). Poorer outcomes are commonly observed among the elderly and individuals with co-morbidities (11-14). Those unable to clear the virus become critical and frequently develop Acute Respiratory Distress Syndrome (ARDS) (15-17). While immunological characteristics of COVID-19 continue to be discovered with ongoing research, the findings surrounding a cytokine storm as well as lymphopenia in patients with SARS-CoV-2, have been consistently reported in most studies $(4,11,18-20)$. Elevated pro-inflammatory cytokines are associated with the severity of disease $(13,18,20,21)$.

Natural Killer (NK) cells play a central role in anti-viral immunity. They can lyse virus-infected host cells by inducing apoptosis via several different pathways. Primarily, it can release an array of proteins such as perforin and granzymes by exocytosis, and together these molecules can induce apoptosis of the target cell (22-24). Secondly, NK cells can kill the target by expressing FAS ligand (FasL) and TNF-related apoptosis-inducing ligand (TRAIL) as the executioner molecules, and subsequently initiate signaling down the extrinsic apoptotic pathway $(24,25)$. In addition, NK cells 
are able to secrete pro-inflammatory cytokines, such as IFN- $\gamma$, TNF- $\alpha$, GM-CSF, as well as chemokines (25-28). NK cells show functional plasticity in the context of disease progression by eliciting pro-inflammatory or anti-inflammatory nature (29-32). Due to the reduced frequencies of NK cells found in COVID-19 patients (33-35) and the well-known anti-viral role of NK cells, it is tempting to speculate that the restoration of NK cells and their function would be a plausible solution for COVID-19 patients.

\section{IMMUNE CHARACTERISTICS OF SARS-COV-2 INFECTION}

Postmortem biopsies of SARS-CoV-2 patients have revealed significant injury to alveolar epithelial cells and other signs of alveolar damage and inflammation (36). The target receptor through which SARS-CoV-2 (and SARS-CoV) enter host cells is the Angiotensin-Converting Enzyme 2 (ACE2) receptor; interestingly, this receptor is sparsely found on cells within healthy human lungs $(3,37,38)$. However, several studies reported that the expression of ACE2 receptor in the lung tissue of individuals with respiratory conditions was increased (39-42). It would explain why the virus is successfully able to infect larger areas of lung tissue. The ACE2 receptor is not only limited to lung tissue but has also been identified in various other tissues in the body, including the cornea, gallbladder, heart, kidney, and testis, but it is most frequently distributed in nasal, alveolar, and intestinal epithelial cells $(43,44)$.

In a murine model of SARS-CoV-1 infection, increased production of chemokines was correlated with increased migration of various innate immune cells, including NK cells into the lungs (45). Various studies suggested chemokineinduced infiltration of immune cells in the infected lungs of patients $(3,46-48)$. Furthermore, the inflammatory response was followed by a second round of cytokine secretion several days later, and this is when $\mathrm{T}$ lymphocyte migration to lungs was subsequently observed (45). Other murine coronavirus infection models also reported the migration of NK cells to lung tissue (49). Thus, these patterns of immune cell migration to lungs observed among coronavirus infections allow for speculation regarding potential NK cell migration to lungs at the early stages of the SARS-CoV-2 infection as well. Under homeostatic conditions, human lung NK cells showed highly differentiated, but hyporesponsive phenotypes with continuous, dynamic movement between blood and the lung (50). Seemingly, the high expression of chemokines in the lungs of COVID-19 patients facilitates NK cell migration from the peripheral blood to the lungs. However, a recent single-cell RNAseq data of the major bronchoalveolar lavage fluid (BALF) immune cell types indicated that patients with severe/critical COVID-19 infection contained similar proportions of NK cells compared with healthy controls (51). Notably, NK cell numbers in peripheral blood mononuclear cells (PBMCs) were found significantly reduced in COVID-19 patients with severe disease compared to those with mild disease (52-54). Importantly, those NK cells showed increased expression of inhibitory receptor T-cell immunoglobulin and mucin domain-3 (TIM3) (55). Thus, current evidence indicates a potential contraction of the NK cell population in the circulation of patients with severe SARS-CoV-2 infection (particularly pronounced with disease severity), even if there is no difference in NK cell counts within the lungs.

\section{Potential for NK Apoptosis in SARS-CoV-2 and Other Infections}

Recurrent observation indicates that SARS-CoV-2 patients have lower total lymphocyte and total NK counts in circulation (33$35,56-59)$. A similar reduction in NK cell counts had been previously reported for the SARS-CoV-1 infection $(60,61)$. In a small cohort of three patients, there was an increased expression of apoptotic genes among the PBMCs compared to healthy controls (21). It hints at increased lymphocyte apoptosis in a highly inflammatory milieu. Besides, current evidence supports that ratios of the various immune cell types are shifted during this infection. An increased neutrophil to lymphocyte ratio in the circulation of SARS-CoV-2 patients is associated with poor prognosis $(62,63)$. A case study of a patient with NK cell lymphoma, who was infected with SARS-CoV-2, revealed a reduction in NK clonal cell numbers as well as lymphoma load, putting them in remission; this was reversed once the patient had resolved the infection (64). This phenomenon raises interest in understanding the potential role of SARS-CoV-2 in inducing NK cell apoptosis.

A study performed single-cell sequencing of PBMC from patient groups with either SARS-CoV-2 or Influenza infection. Findings indicate increased levels of apoptotic molecules (XIAP associated factor 1, TNF, and FAS), leading to apoptosis of T cells in the COVID-19 patient group alone (52). Upcoming research should investigate if a similar activation of apoptotic molecules takes place in NK cells of severe and mildly infected SARS-CoV2 patients, compared to naïve or other virally infected groups.

\section{The Dynamics of a Contracting and Expanding NK Population in Viral Infections}

Past evidence demonstrated two contrasting outcomes in which NK cells are able to maintain or contract the size of their population in response to various viral infections (65-69). A severe reduction of $\mathrm{CD} 56^{\mathrm{dim}} \mathrm{NK}$ cells, the major population mediating NK cell cytotoxicity, was observed in chronic human immunodeficiency virus (HIV), hepatitis C virus (HCV), and varicella-zoster virus (VZV) infections in humans (65). Interestingly, this severe, early loss of CD56dim is followed by an increase in CD3-CD56-CD161+ NK cells with low perforin and elevated $\mathrm{SH} 2$ domain-containing inositol 5-phosphatase-1 (SHIP-1) expression in chronic HIV-1 infection (70). It suggests that anergic phenotype is accompanied during the NK cell loss. In contrast, several reports demonstrated NK cell expansion in several viral infections in humans, including cytomegalovirus (CMV), chikungunya, Hepatitis B Virus (HBV), Epstein-Barr (EBV), and hantavirus infections $(1,3)$. In addition, the expanded population in early HIV infection particularly 
expressed increased levels of the activating receptor KIR3DS1 $(71,72)$.

Maintenance or expansion of the population during viral infections might be dependent on stimulation by a ligandinduced activating receptor, resulting in proliferation. Studies in mouse models of NK activating receptor Ly49H and m157 murine CMV (MCMV) glycoprotein have clearly demonstrated the importance of activating-receptor-induced activation to maintain the NK cell population during the prolonged MCMV infection $(65,73)$. Without the ligand-induced stimulation, NK cells seem markedly reduced in mice deficient in $\mathrm{Ly} 49 \mathrm{H}$ during MCMV infection, similar to several viral infections.

During a typical viral infection, pro-inflammatory cytokines, such as Type 1 IFN, IL-12, IL-15, and IL-18, are generally elevated, inducing NK cell blastogenesis in early virus infection (74-76). Presumably, in a later stage following the innate cytokine-driven proliferation, persistent exposure of NK cells to the highly inflammatory milieu induces apoptosis; and stimulating signaling through the activating receptors might save NK cells from dying off by apoptosis. Thus, activating receptors on NK cells are not only required for the delivery of cytotoxicity and cytokine production, but are also required for the maintenance of the overall NK cell population in sustained virus infection. The model with MCMV also identified that the activating NK cell receptor endows NK cells to play a regulatory role. The sustaining NK cells showed a functional shift from proinflammatory to the anti-inflammatory state by producing IL-10. Without the ligand and activating receptor interaction, NK cells are lost during the prolonged infection and cannot take the opportunity to play the regulatory role, resulting in $\mathrm{T}$ cellmediated immunopathology (73). Notably, NK cell loss or NK cell expansion with the functional switch is prominently observed on the stage, subsequent to early NK cell activation. Thus, the self-control circuit linking the presence of viral-specific NK cell receptors to the regulatory role seems ideal to limit collateral damage resulting from heightened immunity. It likely guarantees that NK cells receiving persistent stimulation via the receptors are programmed to change cytokine production profile to an anti-inflammatory orientation. Alternatively, in the absence of such activating receptors, NK cells are removed after their early IFN- $\gamma$ production, thus preventing them from contributing to the cytokine storm.

While the mechanism by which $\mathrm{NK}$ cells are lost during SARS-CoV-2 virus infection remains elusive, recurrent observation of reduced NK cell frequencies and counts in COVID-19 patients might indicate the absence of ligand and activating receptor interaction between infected cells and NK cells. The NK cell loss is unlikely due to the infection-induced apoptosis in NK cells similar to that observed in the influenza virus infection (77) because NK cells do not express the host entry receptor ACE2 (78). It is tempting to speculate that NK cells in SARS-CoV-2 infection cannot recognize viral ligands of the highly mutated virus with pre-determined, germlineencoded, activating NK cell receptors, even though NK cells may kill the virus-infected cells by recognizing stressinducible ligands.
A study that described detailed responses of NK cell to SARSCoV-2 infection, showed that increased proportions of a subset of NK cell types called adaptive NK cells are found in severe but not moderate COVID-19 disease $(55,79)$. The absolute numbers of NK cells were lower in the blood of patients with COVID-19 compared with healthy controls, consistent with other reports. Adaptive NK cells are known to be generated by the epigenetic modification in several key signaling molecules upon CMV infection and sustained for life $(80,81)$. Interestingly, the adaptive NK cells possess an enhanced capacity for antibodydependent cell-mediated cytotoxicity (ADCC) (80-83). While neutralizing antibodies against SARS-CoV-2 infected cells are the target of active investigation, understanding the role of the adaptive NK cells upon recognizing antibody-opsonized infected cells would provide comprehensive insight on NK cell function in COVID-19 patients.

\section{NK Cell Dysfunction in SARS-CoV-2 Infection \\ Inhibitory Pathways}

Evidence indicates high expression of the immune checkpoint inhibitory receptor NKG2A on reduced NK cells in SARS-CoV-2 patients $(84,85)$. NKG2A prevents NK cell cytotoxicity by binding to the non-classical HLA-E molecule (86). A recent study has revealed that the SARS-CoV-2 Spike 1 protein can bind to the HLA-E and reduce NK cell degranulation function through the HLA-E/NKG2A pathway (87). Lung epithelial cells with intracellular expression of this Spike I protein in vitro resulted in an increased expression of HLA-E on its surface as well as an increase in expression of NKG2A (87). Gene expression of other inhibitory receptors such as TIM-3 and LAG-3 are also induced in NK cells from COVID-19 patients (88). Increased expression of those inhibitory receptors has been associated with immune exhaustion in chronic viral infections and may explain another mechanism by which the virus can override anti-viral immune responses (89).

\section{Role of Complement}

Numerous reports have reported significant similarities between the immune profile of COVID-19 and that of sepsis (90). In sepsis, the inflammatory protein $\mathrm{C} 5 \mathrm{a}$ is generated from the cleavage of complement molecule $\mathrm{C} 5$ by the activation of $\mathrm{C} 5$ convertase (91). C5a can be generated via the action of alveolar macrophages and neutrophils, which have properties of the C5 convertase enzyme. One formed, C5a functions as an inflammatory mediator by binding a variety of immune cells expressing C5aR; it induces the production of various cytokines and chemokines in different cell types (91). Upon exposure to a sepsis-like immune environment, a subset of NK cells and NKT cells can display increased expression of $\mathrm{C} 5 \mathrm{aR}$ receptors and increased cytokine production (92), resulting in detrimental roles of NKT and NK cells during early experimental sepsis. A recent study has demonstrated an increase in serum levels of soluble C5a among patients with SARS-CoV-2 infection with respect to disease severity (93). This leads us to speculate a potential role of C5a engagement with $\mathrm{NK}$ and NKT cells, making them 
notoriously contribute to cytokine storm. An ongoing clinical trial (NCT04371367) is investigating the potential reduction in hyperinflammatory response among COVID-19 patients with hypoxemic pneumonia using Avdoralimab, an antibody for C5a receptors.

\section{Loss of Function}

Consistently, SARS-CoV-2 patients reported reduced functional markers of NK cells with fewer NK cells being CD107a ${ }^{+}(\mathrm{a}$ degranulation marker), IFN- $\gamma^{+}, \mathrm{IL}_{-} 2^{+}$, and TNF- $\alpha^{+}$among infected patients compared to healthy controls (85). They also found a lower expression of granzyme B in the NK cells of these patients. Thus, it would be interesting to investigate if the exhausted phenotype is similar to those with low perforin and elevated SHIP-1 expression in chronic HIV-1 infection (70). Furthermore, functional markers of NK cell cytotoxicity, such as perforin expression in NK cells, were found to be even lower among critical patients with intensive care unit (ICU) admission compared to non-ICU patients and healthy controls (94). Interestingly, recovered patients were found to have normal counts of $\mathrm{NK}$ and $\mathrm{CD}^{+} \mathrm{T}$ cells with reduced NKG2A levels (85), indicating potential reversal among recovered patients. Increased pro-inflammatory cytokines, such as IL-6 and IL-8, in the circulation of SARS-CoV-2 patients correlated with decreased cytotoxic functions of NK cells and $\mathrm{CD}^{+} \mathrm{T}$ cells (94). It is possible that the high levels of circulating IL-6 contribute to dampening the cytotoxic functions of these NK cells, as demonstrated previously $(95,96)$. As such, anti-IL-6 therapy could play a role in preventing some of the immune dysfunction observed in such patients (97). Antibodies against the IL-6 or IL-6 receptor, including siltuximab, tocilizumab, and sarilumab, are intensively being tested for therapeutics in COVID-19 patients in multiple settings $(98,99)$. Notably, a study in which five ICU patients received tocilizumab treatment, restored NK cells function, characterized by a significantly increased expression of granzyme A and perforin (35). In this study, an increased lymphocyte count was observed after tocilizumab treatment, but unfortunately, NK cell counts were not measured (35). Clinical trials with a larger number of patients can determine whether the treatment might correct the NK cell loss and dysfunction in COVID-19 patients.

Even though the counts of NK cells were reduced in patients with SARS-CoV-2 infection, they appeared to be activated (100). In particular, the NK cells from infected patients had increased expression of granzyme $\mathrm{A}$ and perforin, but a decreased expression of granzyme B compared to healthy controls. These findings collectively indicate the loss of some but not all functional characteristics of NK cells among SARS-CoV2 patients.

\section{NK CELL-MEDIATED IMMUNOTHERAPY IN SARS-COV-2 INFECTION}

Due to the loss of NK cells in COVID-19 patients, it is straightforward to assume that the restoration of the number of NK cells by infusing ex vivo expanded NK cells into patients can reinstate immune capacity and increase chances of recovery. Numerous studies done previously for NK cell-mediated cancer therapies have already established various protocols for NK cell expansion from several sources, such as placental CD34+ cells, PBMC NK cells, or NK cell lines (101). Besides, NK cells are regarded as an ideal cell type for adoptive cell transfer due to the low risk of graft-versus-host disease (GVHD) (102). Thus, a few clinical trials are ongoing that attempt to infuse NK cells in COVID-19 patients to treat them (ClinicalTrials.gov Identifier: NCT04344548, NCT04365101, NCT04280224). A phase I-II trial is using an infusion of placental stem cell-derived CD34+ NK cells (that have been proliferated in tissue culture); they are aiming to treat symptomatic patients with mild to moderate SARS-CoV-2 infection and the trial will assess safety and efficacy of the therapy (NCT04365101). Another trial (NCT04280224) is using an infusion of NK cells twice a week on patients with SARS-CoV-2 infection who have developed pneumonia. It is unclear if the infusion contains primary NK cells from matched donors or are derived from other sources. The third study (NCT04344548) will be a Phase I-II trial performing adoptive cell transfer of allogenic, primary NK cells derived from healthy donors to COVID-19 patients with moderate to severe symptoms.

Considering the cytokine storm indicative of the highly inflammatory condition in COVID-19 patients, replenishing expanded NK cells should be designed with extreme caution. Although from healthy sources and expanded under controlled conditions, these NK cells will be exposed to the altered and pathogenic immune environment of these patients, with their unique cytokine milieu. This may cause the NK cell functions to become rather detrimental by producing a massive amount of cytokines and chemokines, instead of playing a beneficial role in the killing of infected cells. The MCMV model demonstrating a functional switch of sustained NK cells to anti-inflammatory might provide a hint for a plausible role of infused NK cells by calming the cytokine storm (73). During extended MCMV infection, NK cells are switched to produce the immunoregulatory cytokine IL-10. Mechanistically, the functional switch in NK cells is hardwired to proliferation, guaranteeing that only sustained NK cells can achieve the intrinsic epigenetic changes in the $\mathrm{Il}-10$ gene locus (103). The proliferating NK cells acquire the histone modifications, allowing the chromatic structure of the $\mathrm{Il}-10$ locus from a closed to an open state. Thus, NK cells with the epigenetic modification can functionally switch to regulatory NK cells by producing IL-10 in response to various cytokine stimulations.

Since ex vivo expanded NK cells have robustly divided during expansion by various protocols, the NK cells have presumably obtained the intrinsic epigenetic changes in the $\mathrm{Il}-10$ gene locus and might be able to respond to several cytokines that are known to induce IL-10 production from NK cells. For example, IL-12 can induce NK cells to produce IL-10 during inflammation and parasitic infection $(104,105)$, and IL-21 can also enhance IL-10 production by NK cell in vitro (106). Interestingly, IL-21 


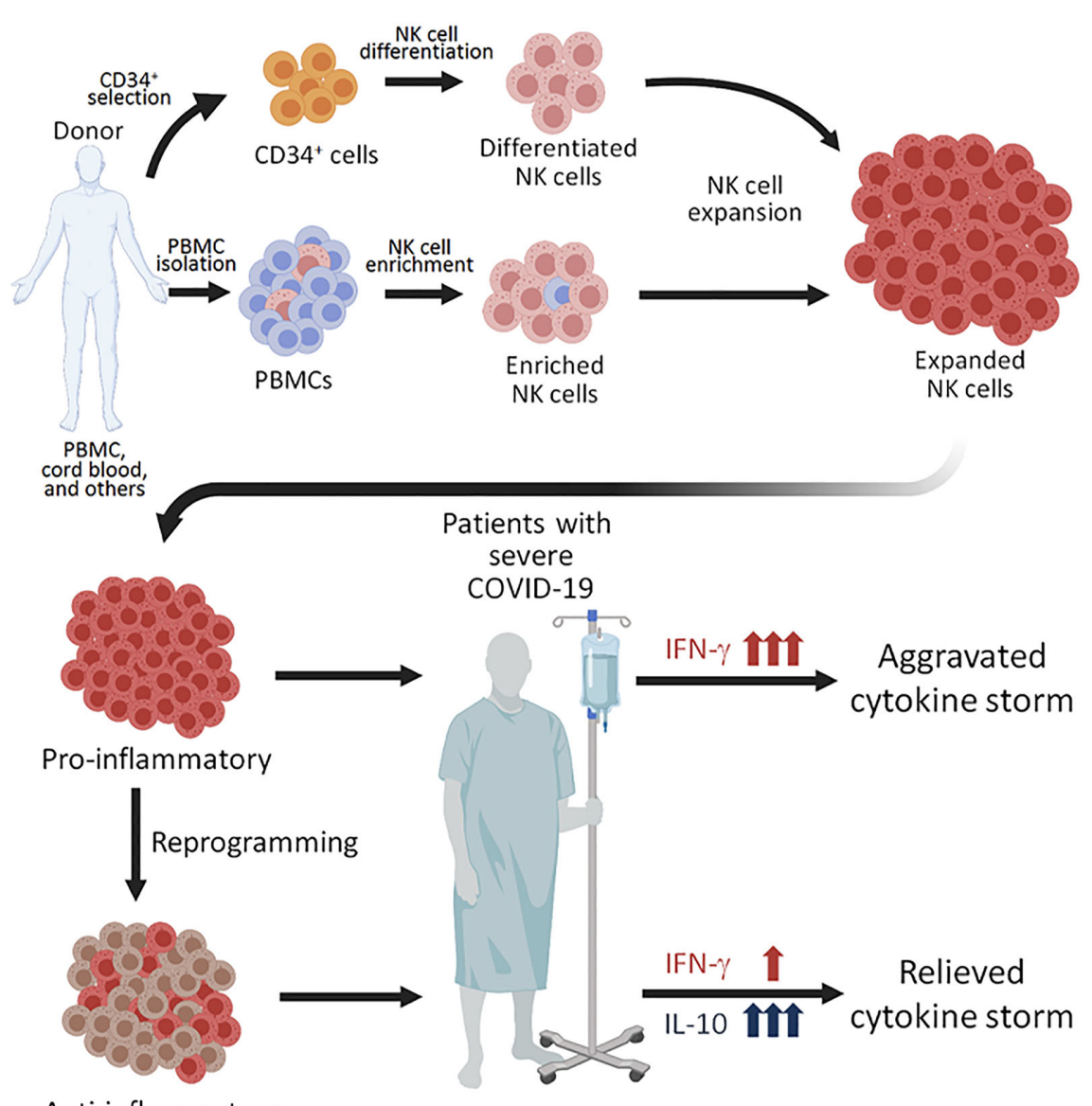

Anti-inflammatory

FIGURE 1 | Proposed NK perfusion therapy to patients with severe COVID-19. NK cells can be obtained by CD56+ cell enrichment from healthy donor's peripheral blood mononuclear cells (PBMCs), differentation of CD34+ hematopoietic progenitors from cord blood, and through other techniques. The NK cells can then be expanded using different combinations of cytokines and irradiated feeder cells. Since expanded NK cells are highly pro-inflammatory, perfusion of such NK cells to COVID-19 patients with severe disease. Alternatively, the expanded NK cells of pro-inflammatory NK cells. The NK cells reprogrammed to produced anti-inflammatory cytokine IL-10 may be more plausible for perfusion treatment for COVID-19 patients with severe disease, who are experiencing a cytokine storm.

treatment on murine NK cells increases both cytotoxicity and IL10 production (106), suggesting a treatment inducing IL-10 without compromising killing capacity of human NK cells. Therefore, pretreatment of expanded NK cells with cytokines to enhance IL-10 response might be an innovative strategy to tailor NK cell response and reduce immunopathology resulting from the excessive production of cytokines in COVID-19 patients (Figure 1).

\section{CONCLUDING REMARKS}

The unprecedented impact of COVID-19 on social, economic, and medical systems urgently requires a deeper understanding of the immune responses associated with SARS-CoV-2 infection, to generate therapeutic responses. Although we remain in the early phases of filling this knowledge gap, some unique characteristics of the disease have begun to be consistently identified. These include the hyperinflammatory response and cytokine storm associated with the disease as well as lower counts of particular immune cells such as NK cells. Nonetheless, it may be naïve to assume that simply restoring NK cell numbers among COVID-19 patients will be sufficient to control the infection. The supplementary NK cells with proinflammatory properties may exaggerate the highly vulnerable situation in COVID-19 patients. Taking advantage of NK cell plasticity, we propose to employ NK cells that are reprogrammed to produce anti-inflammatory cytokine IL-10 in NK cell-mediated therapy. Alternately, NK cells can be reinvigorated by targeting the NKG2A/HLA-E inhibitory pathway. Overall, the review suggests that it is essential to investigate the mechanisms underlying $\mathrm{NK}$ cell losses to 
understand SARS-CoV-2 infection better and to design innovative immunotherapy for COVID-19 patients.

\section{AUTHOR CONTRIBUTIONS}

The review was prepared by the discussion and the consensus of all authors listed. FA and S-HL wrote the manuscript. All authors contributed to the article and approved the submitted version.

\section{REFERENCES}

1. Li H, Liu SM, Yu XH, Tang SL, Tang CK. Coronavirus disease 2019 (COVID-19): current status and future perspectives. Int J Antimicrob Agents (2020), 55(5):105951. doi: 10.1016/j.ijantimicag.2020.105951

2. WHO. Coronavirus disease (COVID-19) pandemic: World Health Organization. (2020) World Health Organization. Available at: https:// www.who.int/emergencies/diseases/novel-coronavirus-2019.

3. Prompetchara E, Ketloy C, Palaga T. Immune responses in COVID-19 and potential vaccines: Lessons learned from SARS and MERS epidemic. Asian Pac J Allergy Immunol (2020) 38(1):1-9. doi: 10.12932/AP-200220-0772

4. Rothan HA, Byrareddy SN. The epidemiology and pathogenesis of coronavirus disease (COVID-19) outbreak. J Autoimmun (2020) 109:102433. doi: 10.1016/j.jaut.2020.102433

5. Zhu M. SARS Immunity and Vaccination. Cell Mol Immunol (2004) 1 (3):193-8

6. Mackay IM, Arden KE. MERS coronavirus: diagnostics, epidemiology and transmission. Virol J (2015) 12:222. doi: 10.1186/s12985-015-0439-5

7. Cascella M, Rajnik M, Cuomo A, Dulebohn SC, Di Napoli R. Features, Evaluation and Treatment Coronavirus (COVID-19). Treasure Island (FL: StatPearls (2020).

8. Pan L, Mu M, Yang P, Sun Y, Wang R, Yan J, et al. Clinical Characteristics of COVID-19 Patients With Digestive Symptoms in Hubei, China: A Descriptive, Cross-Sectional, Multicenter Study. Am J Gastroenterol (2020) 115(5):766-73. doi: 10.14309/ajg.0000000000000620

9. Bermejo-Martin JF, Almansa R, Menendez R, Mendez R, Kelvin DJ, Torres A. Lymphopenic community acquired pneumonia as signature of severe COVID-19 infection. J Infect (2020) 80(5):e23-e4. doi: 10.1016/ j.jinf.2020.02.029

10. Jin X, Lian JS, Hu JH, Gao J, Zheng L, Zhang YM, et al. Epidemiological, clinical and virological characteristics of 74 cases of coronavirus-infected disease 2019 (COVID-19) with gastrointestinal symptoms. Gut (2020) 69 (6):1002-9. doi: 10.1136/gutjnl-2020-320926

11. Felsenstein S, Herbert JA, McNamara PS, Hedrich CM. COVID-19: Immunology and treatment options. Clin Immunol (2020) 215:108448. doi: 10.1016/j.clim.2020.108448

12. Shahid Z, Kalayanamitra R, McClafferty B, Kepko D, Ramgobin D, Patel R, et al. COVID-19 and Older Adults: What We Know. J Am Geriatr Soc (2020) 68(5):926-9. doi: 10.1111/jgs.16472

13. Li X, Xu S, Yu M, Wang K, Tao Y, Zhou Y, et al. Risk factors for severity and mortality in adult COVID-19 inpatients in Wuhan. J Allergy Clin Immunol (2020) 146(1):110-8. doi: 10.1016/j.jaci.2020.04.006

14. Hu L, Chen S, Fu Y, Gao Z, Long H, Wang JM, et al. Risk Factors Associated with Clinical Outcomes in 323 COVID-19 Hospitalized Patients in Wuhan, China. Clin Infect Dis (2020) 71(16):2089-98. doi: 10.1093/cid/ciaa539

15. Leisman DE, Deutschman CS, Legrand M. Facing COVID-19 in the ICU: vascular dysfunction, thrombosis, and dysregulated inflammation. Intensive Care Med (2020) 46:1105-8. doi: 10.1007/s00134-020-06059-6

16. Yang X, Yu Y, Xu J, Shu H, Xia J, Liu H, et al. Clinical course and outcomes of critically ill patients with SARS-CoV-2 pneumonia in Wuhan, China: a single-centered, retrospective, observational study. Lancet Respir Med (2020) 8(5):475-81. doi: 10.1016/S2213-2600(20)30079-5

17. Marini JJ, Gattinoni L. Management of COVID-19 Respiratory Distress. JAMA (2020) 323(22):2329-30. doi: 10.1001/jama.2020.6825

\section{FUNDING}

This work was supported by funding from the Canadian Institutes of Health Research (PJT-156106) to S-HL. The University of Ottawa covered $50 \%$ of the article processing charge.

\section{ACKNOWLEDGMENTS}

The figure was created with BioRender.com.

18. Del Valle DM, Kim-Schulze S, Huang HH. An inflammatory cytokine signature predicts COVID-19 severity and survival. Nat Med (2020) 26:1636-43. doi: 10.1038/s41591-020-1051-9

19. Mehta P, McAuley DF, Brown M, Sanchez E, Tattersall RS, Manson JJ, et al. COVID-19: consider cytokine storm syndromes and immunosuppression. Lancet (2020) 395(10229):1033-4. doi: 10.1016/S0140-6736(20)30628-0

20. Hirano T, Murakami M. COVID-19: A New Virus, but a Familiar Receptor and Cytokine Release Syndrome. Immunity (2020) 52(5):731-3. doi: 10.1016/j.immuni.2020.04.003

21. Xiong Y, Liu Y, Cao L, Wang D, Guo M, Jiang A, et al. Transcriptomic characteristics of bronchoalveolar lavage fluid and peripheral blood mononuclear cells in COVID-19 patients. Emerg Microbes Infect (2020) 9 (1):761-70. doi: 10.1080/22221751.2020.1747363

22. Prager I, Liesche C, van Ooijen H, Urlaub D, Verron Q, Sandstrom N, et al. NK cells switch from granzyme B to death receptor-mediated cytotoxicity during serial killing. J Exp Med (2019) 216(9):2113-27. doi: 10.1084/ jem.20181454

23. Rudd-Schmidt JA, Trapani JA, Voskoboinik I. Distinguishing perforinmediated lysis and granzyme-dependent apoptosis. Methods Enzymol (2019) 629:291-306. doi: 10.1016/bs.mie.2019.07.034

24. Lee SH, Miyagi T, Biron CA. Keeping NK cells in highly regulated antiviral warfare. Trends Immunol (2007) 28(6):252-9. doi: 10.1016/j.it.2007.04.001

25. Prager I, Watzl C. Mechanisms of natural killer cell-mediated cellular cytotoxicity. J Leukoc Biol (2019) 105(6):1319-29. doi: 10.1002/ JLB.MR0718-269R

26. Hammer Q, Romagnani C. About Training and Memory: NK-Cell Adaptation to Viral Infections. Adv Immunol (2017) 133:171-207. doi: 10.1016/bs.ai.2016.10.001

27. Vivier E, Tomasello E, Baratin M, Walzer T, Ugolini S. Functions of natural killer cells. Nat Immunol (2008) 9(5):503-10. doi: 10.1038/ni1582

28. Abel AM, Yang C, Thakar MS, Malarkannan S. Natural Killer Cells: Development, Maturation, and Clinical Utilization. Front Immunol (2018) 9:1869:1869. doi: 10.3389/fimmu.2018.01869

29. Pfefferle A, Jacobs B, Netskar H, Ask EH, Lorenz S, Clancy T, et al. Intralineage Plasticity and Functional Reprogramming Maintain Natural Killer Cell Repertoire Diversity. Cell Rep (2019) 29(8):2284-94 e4. doi: 10.1016/ j.celrep.2019.10.058

30. Clark SE, Burrack KS, Jameson SC, Hamilton SE, Lenz LL. NK Cell IL-10 Production Requires IL-15 and IL-10 Driven STAT3 Activation. Front Immunol (2019) 10:2087:2087. doi: 10.3389/fimmu.2019.02087

31. Deniz G, Akdis M, Aktas E, Blaser K, Akdis CA. Human NK1 and NK2 subsets determined by purification of IFN-gamma-secreting and IFNgamma-nonsecreting NK cells. Eur J Immunol (2002) 32(3):879-84. doi: 10.1002/1521-4141(200203)32:3<879::AID-IMMU879>3.0.CO;2-2

32. Mocellin S, Panelli M, Wang E, Rossi CR, Pilati P, Nitti D, et al. IL-10 stimulatory effects on human NK cells explored by gene profile analysis. Genes Immun (2004) 5(8):621-30. doi: 10.1038/sj.gene.6364135

33. Song JW, Zhang C, Fan X, Meng FP, Xu Z, Xia P, et al. Immunological and inflammatory profiles in mild and severe cases of COVID-19. Nat Commun (2020) 11(1):3410. doi: 10.1038/s41467-020-17240-2

34. Giamarellos-Bourboulis EJ, Netea MG, Rovina N, Akinosoglou K, Antoniadou A, Antonakos $\mathrm{N}$, et al. Complex Immune Dysregulation in COVID-19 Patients with Severe Respiratory Failure. Cell Host Microbe (2020) 27(6):992-1000.e3. doi: 10.1016/j.chom.2020.04.009 
35. Mazzoni A, Salvati L, Maggi L, Capone M, Vanni A, Spinicci M, et al. Impaired immune cell cytotoxicity in severe COVID-19 is IL-6 dependent. J Clin Invest (2020) 130(9):4694-703. doi: 10.1172/JCI138554

36. Tian S, Xiong Y, Liu H, Niu L, Guo J, Liao M, et al. Pathological study of the 2019 novel coronavirus disease (COVID-19) through postmortem core biopsies. Mod Pathol (2020) 33(6):1007-14. doi: 10.1038/s41379-0200536-x

37. Lu R, Zhao X, Li J, Niu P, Yang B, Wu H, et al. Genomic characterisation and epidemiology of 2019 novel coronavirus: implications for virus origins and receptor binding. Lancet (2020) 395(10224):565-74. doi: 10.1016/S01406736(20)30251-8

38. Wan Y, Shang J, Graham R, Baric RS, Li F. Receptor Recognition by the Novel Coronavirus from Wuhan: an Analysis Based on Decade-Long Structural Studies of SARS Coronavirus. J Virol (2020) 94(7):e00127-20. doi: 10.1128/JVI.00127-20

39. Chua RL, Lukassen S, Trump S. COVID-19 severity correlates with airway epithelium-immune cell interactions identified by single-cell analysis. Nat Biotechnol (2020) 38:970-9. doi: 10.1038/s41587-020-0602-4

40. Radzikowska U, Ding M, Tan G, Zhakparov D, Peng Y, Wawrzyniak P, et al. Distribution of ACE2, CD147, CD26, and other SARS-CoV-2 associated molecules in tissues and immune cells in health and in asthma, COPD, obesity, hypertension, and COVID-19 risk factors. Allergy (2020) 75 (11):2829-45. doi: 10.1111/all.14429

41. Ziegler CGK, Allon SJ, Nyquist SK, Mbano IM, Miao VN, Tzouanas CN, et al. SARS-CoV-2 Receptor ACE2 Is an Interferon-Stimulated Gene in Human Airway Epithelial Cells and Is Detected in Specific Cell Subsets across Tissues. Cell (2020) 181(5):1016-35 e19. doi: 10.1016/ j.cell.2020.04.035

42. Chua RL, Lukassen S, Trump S, Hennig BP, Wendisch D, Pott F, et al. COVID-19 severity correlates with airway epithelium-immune cell interactions identified by single-cell analysis. Nat Biotechnol (2020) 38 (8):970-9. doi: 10.1038/s41587-020-0602-4

43. Hamming I, Timens W, Bulthuis ML, Lely AT, Navis G, van Goor H. Tissue distribution of ACE2 protein, the functional receptor for SARS coronavirus. A first step in understanding SARS pathogenesis. J Pathol (2004) 203 (2):631-7. doi: 10.1002/path.1570

44. Sungnak W, Huang N, Becavin C, Berg M, Queen R, Litvinukova M, et al. SARS-CoV-2 entry factors are highly expressed in nasal epithelial cells together with innate immune genes. Nat Med (2020) 26(5):681-7. doi: 10.1038/s41591-020-0868-6

45. Chen J, Lau YF, Lamirande EW, Paddock CD, Bartlett JH, Zaki SR, et al. Cellular immune responses to severe acute respiratory syndrome coronavirus (SARS-CoV) infection in senescent BALB/c mice: $\mathrm{CD} 4+\mathrm{T}$ cells are important in control of SARS-CoV infection. J Virol (2010) 84 (3):1289-301. doi: 10.1128/JVI.01281-09

46. Cao X. COVID-19: immunopathology and its implications for therapy. Nat Rev Immunol (2020) 20(5):269-70. doi: 10.1038/s41577-020-0308-3

47. Ye Q, Wang B, Mao J. The pathogenesis and treatment of the 'Cytokine Storm' in COVID-19. J Infect (2020) 80(6):607-13. doi: 10.1016/ j.jinf.2020.03.037

48. Tufan A, Avanoglu Guler A, Matucci-Cerinic M. COVID-19, immune system response, hyperinflammation and repurposing antirheumatic drugs. Turk J Med Sci (2020) 50(SI-1):620-32. doi: 10.3906/sag-2004-168

49. Hua X, Vijay R, Channappanavar R, Athmer J, Meyerholz DK, Pagedar N, et al. Nasal priming by a murine coronavirus provides protective immunity against lethal heterologous virus pneumonia. JCI Insight (2018) 3(11): e99025. doi: 10.1172/jci.insight.99025

50. Marquardt N, Kekalainen E, Chen P, Kvedaraite E, Wilson JN, Ivarsson MA, et al. Human lung natural killer cells are predominantly comprised of highly differentiated hypofunctional CD69(-)CD56(dim) cells. J Allergy Clin Immunol (2017) 139(4):1321-30 e4. doi: 10.1016/j.jaci.2016.07.043

51. Liao M, Liu Y, Yuan J, Wen Y, Xu G, Zhao J, et al. Single-cell landscape of bronchoalveolar immune cells in patients with COVID-19. Nat Med (2020) 26(6):842-4. doi: 10.1038/s41591-020-0901-9

52. Taghiloo S, Aliyali M, Abedi S, Mehravaran H, Sharifpour A, Zaboli E, et al. Apoptosis and immunophenotyping of peripheral blood lymphocytes in Iranian COVID-19 patients: Clinical and laboratory characteristics. J Med Virol (2020). doi: 10.1002/jmv.26505
53. Huang W, Berube J, McNamara M, Saksena S, Hartman M, Arshad T, et al. Lymphocyte Subset Counts in COVID-19 Patients: A Meta-Analysis. Cytometry A (2020) 97(8):772-6. doi: 10.1002/cyto.a.24172

54. Wang F, Nie J, Wang H, Zhao Q, Xiong Y, Deng L, et al. Characteristics of Peripheral Lymphocyte Subset Alteration in COVID-19 Pneumonia. J Infect Dis (2020) 221(11):1762-9. doi: 10.1093/infdis/jiaa150

55. Varchetta S, Mele D, Oliviero B, Mantovani S, Ludovisi S, Cerino A, et al. Unique immunological profile in patients with COVID-19. Cell Mol Immunol (2020). doi: 10.1038/s41423-020-00557-9

56. Tay MZ, Poh CM, Renia L, MacAry PA, Ng LFP. The trinity of COVID-19: immunity, inflammation and intervention. Nat Rev Immunol (2020) 20 (6):363-74. doi: 10.1038/s41577-020-0311-8

57. Qin C, Zhou L, Hu Z, Zhang S, Yang S, Tao Y, et al. Dysregulation of immune response in patients with COVID-19 in Wuhan, China. Clin Infect Dis (2020) 71(15):762-8. doi: 10.1093/cid/ciaa248

58. Chen N, Zhou M, Dong X, Qu J, Gong F, Han Y, et al. Epidemiological and clinical characteristics of 99 cases of 2019 novel coronavirus pneumonia in Wuhan, China: a descriptive study. Lancet (2020) 395(10223):507-13. doi: 10.1016/S0140-6736(20)30211-7

59. Guan WJ, Ni ZY, Hu Y, Liang WH, Ou CQ, He JX, et al. Clinical Characteristics of Coronavirus Disease 2019 in China. N Engl J Med (2020) 382(18):1708-20. doi: 10.1056/NEJMoa2002032

60. He Z, Zhao C, Dong Q, Zhuang H, Song S, Peng G, et al. Effects of severe acute respiratory syndrome (SARS) coronavirus infection on peripheral blood lymphocytes and their subsets. Int J Infect Dis (2005) 9(6):323-30. doi: $10.1016 /$ j.ijid.2004.07.014

61. National Research Project for SARS BG. The involvement of natural killer cells in the pathogenesis of severe acute respiratory syndrome. Am J Clin Pathol (2004) 121(4):507-11. doi: 10.1309/WPK7-Y2XK-NF4C-BF3R

62. Liu Y, Du X, Chen J, Jin Y, Peng L, Wang HHX, et al. Neutrophil-tolymphocyte ratio as an independent risk factor for mortality in hospitalized patients with COVID-19. J Infect (2020) 81(1):e6-e12. doi: 10.1016/ j.jinf.2020.04.002

63. Lagunas-Rangel FA. Neutrophil-to-lymphocyte ratio and lymphocyte-to-Creactive protein ratio in patients with severe coronavirus disease 2019 (COVID-19): A meta-analysis. J Med Virol (2020). doi: 10.1002/jmv.25819

64. Pasin F, Mascalchi Calveri M, Calabrese A, Pizzarelli G, Bongiovanni I, Andreoli M, et al. Oncolytic effect of SARS-CoV2 in a patient with NK lymphoma. Acta BioMed (2020) 91(3). doi: 10.23750/abm.v91i3.10141

65. Lee $\mathrm{SH}$, Biron CA. Here today-not gone tomorrow: roles for activating receptors in sustaining NK cells during viral infections. Eur J Immunol (2010) 40(4):923-32. doi: 10.1002/eji.201040304

66. Cook KD, Whitmire JK. The depletion of NK cells prevents T cell exhaustion to efficiently control disseminating virus infection. J Immunol (2013) 190 (2):641-9. doi: 10.4049/jimmunol.1202448

67. Bjorkstrom NK, Lindgren T, Stoltz M, Fauriat C, Braun M, Evander M, et al. Rapid expansion and long-term persistence of elevated NK cell numbers in humans infected with hantavirus. J Exp Med (2011) 208(1):13-21. doi: $10.1084 /$ jem.20100762

68. Adams NM, Grassmann S, Sun JC. Clonal expansion of innate and adaptive lymphocytes. Nat Rev Immunol (2020) 20(11):694-707. doi: 10.1038/ s41577-020-0307-4

69. Amorim CF, Carvalho NB, Neto JA, Santos SB, Grassi MFR, Carvalho LP, et al. The Role of NK Cells in the Control of Viral Infection in HTLV-1 Carriers. J Immunol Res (2019) 2019:6574828. doi: 10.1155/ 2019/6574828

70. Alter G, Suscovich TJ, Kleyman M, Teigen N, Streeck H, Zaman MT, et al. Low perforin and elevated SHIP-1 expression is associated with functional anergy of natural killer cells in chronic HIV-1 infection. AIDS (2006) 20 (11):1549-51. doi: 10.1097/01.aids.0000237371.31315.48

71. Alter G, Martin MP, Teigen N, Carr WH, Suscovich TJ, Schneidewind A, et al. Differential natural killer cell-mediated inhibition of HIV-1 replication based on distinct KIR/HLA subtypes. J Exp Med (2007) 204(12):3027-36. doi: 10.1084/jem.20070695

72. Alter G, Rihn S, Walter K, Nolting A, Martin M, Rosenberg ES, et al. HLA class I subtype-dependent expansion of KIR3DS1+ and KIR3DL1+ NK cells during acute human immunodeficiency virus type 1 infection. J Virol (2009) 83(13):6798-805. doi: 10.1128/JVI.00256-09 
73. Lee SH, Kim KS, Fodil-Cornu N, Vidal SM, Biron CA. Activating receptors promote NK cell expansion for maintenance, IL-10 production, and CD8 T cell regulation during viral infection. J Exp Med (2009) 206(10):2235-51. doi: 10.1084/jem.20082387

74. Biron CA, Nguyen KB, Pien GC, Cousens LP, Salazar-Mather TP. Natural killer cells in antiviral defense: function and regulation by innate cytokines. Annu Rev Immunol (1999) 17:189-220. doi: 10.1146/annurev.immunol. 17.1.189

75. Hammer Q, Ruckert T, Romagnani C. Natural killer cell specificity for viral infections. Nat Immunol (2018) 19(8):800-8. doi: 10.1038/s41590-018-0163-6

76. Zwirner NW, Ziblat A. Regulation of NK Cell Activation and Effector Functions by the IL-12 Family of Cytokines: The Case of IL-27. Front Immunol (2017) 8:25:25. doi: 10.3389/fimmu.2017.00025

77. Mao H, Tu W, Qin G, Law HK, Sia SF, Chan PL, et al. Influenza virus directly infects human natural killer cells and induces cell apoptosis. J Virol (2009) 83(18):9215-22. doi: 10.1128/JVI.00805-09

78. Travaglini KJ, Nabhan AN, Penland L, Sinha R, Gillich A, Sit RV, et al. A molecular cell atlas of the human lung from single cell RNA sequencing. bioRxiv (2020). doi: 10.1101/742320

79. Maucourant C, Filipovic I, Ponzetta A, Aleman S, Cornillet M, Hertwig L, et al. Natural killer cell immunotypes related to COVID-19 disease severity. Sci Immunol (2020) 5(50):eabd6832. doi: 10.1126/sciimmunol. abd6832

80. Lee J, Zhang T, Hwang I, Kim A, Nitschke L, Kim M, et al. Epigenetic modification and antibody-dependent expansion of memory-like NK cells in human cytomegalovirus-infected individuals. Immunity (2015) 42(3):43142. doi: 10.1016/j.immuni.2015.02.013

81. Schlums H, Cichocki F, Tesi B, Theorell J, Beziat V, Holmes TD, et al. Cytomegalovirus infection drives adaptive epigenetic diversification of NK cells with altered signaling and effector function. Immunity (2015) 42 (3):443-56. doi: 10.1016/j.immuni.2015.02.008

82. Hwang I, Zhang T, Scott JM, Kim AR, Lee T, Kakarla T, et al. Identification of human NK cells that are deficient for signaling adaptor FcRgamma and specialized for antibody-dependent immune functions. Int Immunol (2012) 24(12):793-802. doi: 10.1093/intimm/dxs080

83. Zhang T, Scott JM, Hwang I, Kim S. Cutting edge: antibody-dependent memory-like NK cells distinguished by FcRgamma deficiency. J Immunol (2013) 190(4):1402-6. doi: 10.4049/jimmunol.1203034

84. Yaqinuddin A, Kashir J. Innate immunity in COVID-19 patients mediated by NKG2A receptors, and potential treatment using Monalizumab, Cholroquine, and antiviral agents. Med Hypotheses (2020) 140:109777. doi: 10.1016/j.mehy.2020.109777

85. Zheng M, Gao Y, Wang G, Song G, Liu S, Sun D, et al. Functional exhaustion of antiviral lymphocytes in COVID-19 patients. Cell Mol Immunol (2020) 17 (5):533-5. doi: 10.1038/s41423-020-0402-2

86. Braud VM, Allan DS, O'Callaghan CA, Soderstrom K, D'Andrea A, Ogg GS, et al. HLA-E binds to natural killer cell receptors CD94/NKG2A, B and C. Nature (1998) 391(6669):795-9. doi: 10.1038/35869

87. Bortolotti D, Gentili V, Rizzo S, Rotola A, Rizzo R. SARS-CoV-2 Spike 1 Protein Controls Natural Killer Cell Activation via the HLA-E/NKG2A Pathway. Cells (2020) 9(9):1975. doi: 10.3390/cells9091975

88. Wilk AJ, Rustagi A, Zhao NQ, Roque J, Martinez-Colon GJ, McKechnie JL, et al. A single-cell atlas of the peripheral immune response in patients with severe COVID-19. Nat Med (2020) 26(7):1070-6. doi: 10.1038/s41591-0200944-y

89. Bi J, Tian Z. NK Cell Dysfunction and Checkpoint Immunotherapy. Front Immunol (2019) 10:1999:1999. doi: 10.3389/fimmu.2019.01999

90. Lopez-Collazo E, Avendano-Ortiz J, Martin-Quiros A, Aguirre LA. Immune Response and COVID-19: A mirror image of Sepsis. Int J Biol Sci (2020) 16 (14):2479-89. doi: 10.7150/ijbs.48400

91. Yan C, Gao H. New insights for C5a and C5a receptors in sepsis. Front Immunol (2012) 3:368. doi: 10.3389/fimmu.2012.00368
92. Fusakio ME, Mohammed JP, Laumonnier Y, Hoebe K, Kohl J, Mattner J. C5a regulates NKT and NK cell functions in sepsis. J Immunol (2011) 187 (11):5805-12. doi: 10.4049/jimmunol.1100338

93. Carvelli J, Demaria O, Vely F, Batista L, Benmansour NC, Fares J, et al. Association of COVID-19 inflammation with activation of the C5a-C5aR1 axis. Nature (2020). doi: 10.1038/s41586-020-2600-6

94. Bordoni V, Sacchi A, Cimini E, Notari S, Grassi G, Tartaglia E, et al. An inflammatory profile correlates with decreased frequency of cytotoxic cells in COVID-19. Clin Infect Dis (2020) 71(16):2272-5. doi: 10.1093/cid/ciaa577

95. Cifaldi L, Prencipe G, Caiello I, Bracaglia C, Locatelli F, De Benedetti F, et al. Inhibition of natural killer cell cytotoxicity by interleukin-6: implications for the pathogenesis of macrophage activation syndrome. Arthritis Rheumatol (2015) 67(11):3037-46. doi: 10.1002/art.39295

96. Kang YJ, Jeung IC, Park A, Park YJ, Jung H, Kim TD, et al. An increased level of IL-6 suppresses NK cell activity in peritoneal fluid of patients with endometriosis via regulation of SHP-2 expression. Hum Reprod (2014) 29 (10):2176-89. doi: 10.1093/humrep/deu172

97. Cunningham L, Kimber I, Basketter DA, McFadden JP. Why judiciously timed anti-IL 6 therapy may be of benefit in severe COVID-19 infection. Autoimmun Rev (2020) 19(7):102563. doi: 10.1016/j.autrev.2020.102563

98. Michot JM, Albiges L, Chaput N, Saada V, Pommeret F, Griscelli F, et al. Tocilizumab, an anti-IL-6 receptor antibody, to treat COVID-19-related respiratory failure: a case report. Ann Oncol (2020) 31(7):961-4. doi: 10.1016/j.annonc.2020.03.300

99. Campochiaro C, Della-Torre E, Cavalli G, De Luca G, Ripa M, Boffini N, et al. Efficacy and safety of tocilizumab in severe COVID-19 patients: a single-centre retrospective cohort study. Eur J Intern Med (2020) 76:43-9. doi: 10.1016/j.ejim.2020.05.021

100. Jiang Y, Wei X, Guan J, Qin S, Wang Z, Lu H, et al. COVID-19 pneumonia: $\mathrm{CD} 8(+) \mathrm{T}$ and NK cells are decreased in number but compensatory increased in cytotoxic potential. Clin Immunol (2020), 108516. doi: 10.1016/ j.clim.2020.108516

101. Shimasaki N, Jain A, Campana D. NK cells for cancer immunotherapy. Nat Rev Drug Discovery (2020) 19(3):200-18. doi: 10.1038/s41573-019-0052-1

102. Simonetta F, Alvarez M, Negrin RS. Natural Killer Cells in Graft-versusHost-Disease after Allogeneic Hematopoietic Cell Transplantation. Front Immunol (2017) 8:465:465. doi: 10.3389/fimmu.2017.00465

103. Tarrio ML, Lee SH, Fragoso MF, Sun HW, Kanno Y, O'Shea JJ, et al Proliferation conditions promote intrinsic changes in NK cells for an IL10 response. J Immunol (2014) 193(1):354-63. doi: 10.4049/jimmunol. 1302999

104. Perona-Wright G, Mohrs K, Szaba FM, Kummer LW, Madan R, Karp CL, et al. Systemic but not local infections elicit immunosuppressive IL-10 production by natural killer cells. Cell Host Microbe (2009) 6(6):503-12. doi: 10.1016/j.chom.2009.11.003

105. Grant LR, Yao ZJ, Hedrich CM, Wang F, Moorthy A, Wilson K, et al. Stat4dependent, T-bet-independent regulation of IL-10 in NK cells. Genes Immun (2008) 9(4):316-27. doi: 10.1038/gene.2008.20

106. Brady J, Hayakawa Y, Smyth MJ, Nutt SL. IL-21 induces the functional maturation of murine NK cells. J Immunol (2004) 172(4):2048-58. doi: 10.4049/jimmunol.172.4.2048

Conflict of Interest: The authors declare that the research was conducted in the absence of any commercial or financial relationships that could be construed as a potential conflict of interest.

Copyright (c) 2020 Ahmed, Jo and Lee. This is an open-access article distributed under the terms of the Creative Commons Attribution License (CC BY). The use, distribution or reproduction in other forums is permitted, provided the original author(s) and the copyright owner(s) are credited and that the original publication in this journal is cited, in accordance with accepted academic practice. No use, distribution or reproduction is permitted which does not comply with these terms. 